\title{
Development of a VR Prototype for Enhancing Earthquake Evacuee Safety
}

\author{
Hui Liang ${ }^{\dagger}$ \\ Zhengzhou University of Light \\ Industry \\ Zhengzhou, China \\ Changhai Wang \\ Zhengzhou University of Light \\ Industry \\ Zhengzhou, China
}

\author{
Fei Liang \\ Zhengzhou University of Light \\ Industry \\ Zhengzhou, China
}

\author{
Jian Chang \\ Bournemouth University \\ Poole, UK
}

\author{
Fenglong $\mathrm{Wu}$ \\ Zhengzhou University of Light \\ Industry \\ Zhengzhou, China
}

\begin{abstract}
Training and education for enhancing evacuee safety is essential to reduce deaths, injuries and damages from disasters, such as fire and earthquake. However, traditional training approaches, e.g. evacuation drills, hardly simulate the real world emergency, which lead to the limitation of reality and poor interaction. In addition, traditional approaches may not provide investigation of participants' behavior during evacuations and give feedback after training. As a novel and effective alternative to overcome these limitations, in this paper, a VR-based training prototype system is designed and implemented for enhance earthquake evacuation safety. Key modules including earthquake scenario simulation, damage representation, interaction, player investigation and feedback are developed. In the immersive VR environment, players can be provided with learning outcomes as well as behavior feedback as crucial goals for safety training. Based on the result of the evaluation, this prototype has proven to be promising for enhancing earthquake evacuee safety and shows positive pedagogical functions.
\end{abstract}

\section{CCS CONCEPTS}

- Human-centered computing Virtual reality • Software and its engineering $\sim$ Virtual worlds training simulations

\section{KEYWORDS}

Virtual Reality, Prototype Development, Earthquake Evacuation, Safety Training

\section{ACM Reference format:}

Hui Liang, Fei Liang, Fenglong Wu, Changhai Wang and Jian Chang. 2018. Development of a VR Prototype for Enhancing Earthquake Evacuee Safety. In Proceedings of ACM VRCAI conference (VRCAI'18). ACM, New York, NY, USA, 8 pages. https://doi.org/10.1145/1234567890

\section{Introduction}

†Corresponding author: hliang@zzuli.edu.cn
Earthquake caused widespread damage every year. The effects of earthquakes includes shaking and ground rupture, landslides and avalanches, floods and fires, bridge, road and property damage (Lovreglio et al. 2017). Besides these damages to landforms and infrastructure, more seriously, an earthquake may cause injury and loss of life. People were even buried by collapsed buildings caused by the main shock of Christchurch quake happened in New Zealand in 2011 (Koubaridis 2011). Earthquakes can also cause fires by damaging electrical power or gas lines. With poisonous smoke produced and oxygen burn at a high temperature, fire may block the primary evacuation route of the building. If not be trained in the workplace layout and familiar with the emergency evacuation procedures, the building occupants can hardly find the various alternative escape routes in this emergency situation. A disastrous example occurred in 1906, more deaths were caused by fire than by the earthquake itself in the San Francisco earthquake (USGS 2018).

Educational approaches, such as evacuation drills, are often used to train the occupants and provide them with information about safety procedures. However, traditional approaches are easy to fail from a pedagogical standpoint (Mitsuhara et al. 2015). For example, when carrying out a drill in a healthcare environment, occupants cannot easily leave the hospital buildings. Vulnerable occupants even may possibly be confronted with potential dangerous in such simulated emergency evacuation (Foronda et al. 2016; Lovreglio et al. 2016; Gwynne et al. 2017). Furthermore, evacuation drills are generally costly, and it is difficult to ensure that evacuation drill participants are under effective training. The difference between the real world earthquake emergency and the simulated emergency in evacuation drill has been identified as a major reason for this pedagogical limitation (Lovreglio et al. 2017). Traditional evacuation drill approach can hardly take into account the building damage and its impact on human behavior (Bernardini 2016), provide feedback to evacuation drill participants and assess their evacuation choices (Gwynne et al. 2016; Gwynne et al. 2017).

Advanced Virtual Reality (VR) and Serious Games (SG) technologies represent effective alternatives to traditional approaches to 
enhance safety by overcoming the limitations of traditional approaches (Gwynne et al. 2017; Foronda et al. 2016), which provides us with novel and effective platform to train building occupants to cope with earthquake evacuations for enhancing safety. In this paper, conceptual and technical approaches are developed to implement a VR-based prototype for earthquake evacuation training. Our system allows participants experience more realistic evacuation scenarios by representing several threats, e.g. fire and object falling, caused by earthquake without exposing them to any risk. Having education as the primary goal, through navigation interactions the prototype provides players with knowledge on wayfinding and exit choice to evacuate safely. As a high controllable training tool, the system can also investigate player's behavior in simulated emergence scenarios. By comparing player's escape route with the auto-generated optimal evacuation path plan, system can provide feedback to participants to assess their evacuation choices to enhance the training outcomes.

The remainder of the paper is organized as follows: In Section 2, we review related work on VR/SG-based earthquake evacuation training. Section 3 describes in detail the developed prototype including the architecture, virtual environment design, related algorithms, and implementation techniques. In Section 4, we present examples and discuss the result. Section 5 concludes the paper. We would like to claim the following contributions in this paper:

- A novel VR-based prototype to train building occupants to cope with earthquake evacuation, without risk from real world;

- An effective evacuation route evaluation algorithm to provide feedback to trainees for enhancing earthquake evacuee safety;

\section{Related Work}

Traditional training approaches for enhancing earthquake safety include conducting earthquake drills (Ramirez et al. 2009), watching tutorial videos and reading safety manuals (Grant 2001) etc. People are trained to remember what they are supposed to do and how to respond properly when earthquake occurs. However, these traditional approaches cannot provide participants with effective training because of the difference between the real world emergency and the simulated earthquake drills. Furthermore, traditional approaches do not allow for the investigation of evacuation drill participants, and consequently cannot further provide feedback to participants for conducting evaluation, which largely limits the intended learning outcomes (Bernardini et al. 2016; Gwynne et al. 2016; Gwynne et al. 2017).

Nowadays VR and SGs are widely used in the field of education (Bertram et al. 2015) and virtual training (Pan et al. 2005), which represents a new means to overcome the limitations of traditional approaches. One obvious advantage is that earthquake features, such as ground shaking, object falling, fire and smoke, can easily be simulated in virtual environments, which dramatically improve training realism and provide participants with better immersive experience. At the same time, VR-based approaches can provide the construction of safety training scenarios, where participants can experience without any risk.
By using more immersive devices, e.g. head mounted displays (HMDs), participants are exposed to more realistic evacuation scenarios facing several threats such as fire and earthquake building damage, which help train people to cope with different emergency issues (Williams-Bell et al. 2015) and several evacuation scenarios (Chittaro and Buttussi 2015). VR and SGs have been tested for enhancing players' earthquake preparedness and for training purposes in fire emergencies (Tanes and Cho 2013). For example, 'Beat the Quake!' is an online game training people to take precautions against earthquake developed by the Earthquake Country Alliance (Xu et al. 2014). A cost-effective 3D VR system is designed for military live fire training in (Tanes and Cho 2013). A VR-based training simulator is developed which can provide smoke assessment capability in research of (Bhagat et al. 2016). Li et al. (Li et al. 2017) has proposed an immersive and novel virtual earthquake drills training approach to teach individuals how to survive earthquakes in common indoor environments. Evaluation results show the effectiveness of their approach. However, player's behavior in the VR training environment is not investigated, which is expected to help provide a better understanding on player's performance.

Actually, another advantage provided by VR and SGs platforms is that player's motion data can be collected by simulators. Immersive VR technologies allow the investigation of evacuee movement and even the evacuee viewing directions, which provides the possibility of recognizing players' behaviors (Rüppel and Schatz 2011), such as wayfinding and exit choice during building evacuations (Lovreglio et al. 2016), system perception in evacuation training (Olander et al. 2017; Ronchi et al. 2016), and even which elements and objects the players are looking at when making decisions (Rüppel and Schatz 2011). Once players' behaviors are identified, suggestive feedback will then be provided.

\section{System Design}

In this section, we describe the prototype system design for earthquake evacuation to train building occupants in coping with emergency, and to investigate their behavior during evacuations and give feedback after training.

\subsection{Virtual Earthquake Environment Repre- sentation}

Earthquake generally consists of three seismic stages: the foreshock stage, the main shock and the aftershock stage, some of which can even last several months (Jones 1994). To be compatible with the context of the VR-based prototype design, we focus on the representing the timeframe of the main shock and related evacuation procedure training simulating.

As the main feature of main shock, building shaking is simulated using immersive technologies. Through HMDs-HTC Vive, participant can perceive the earthquake by looking at its impact on the building elements and the movement of furniture in the immersive virtual world. As illustrated in Figure 1, the shaking of the ceiling lamp, table and other elements within the building allows 
participants to sense the shaking experience that they would experience in a real earthquake. Holding HTC Vive controller in hand, players can sense vibrations from the vibration motors of the game controller. Visual and tactile combination generates a relatively high shaking experience. The movement of furniture and falling objects is represented by using physical engine of virtual reality engine Unity $3 \mathrm{D}$.

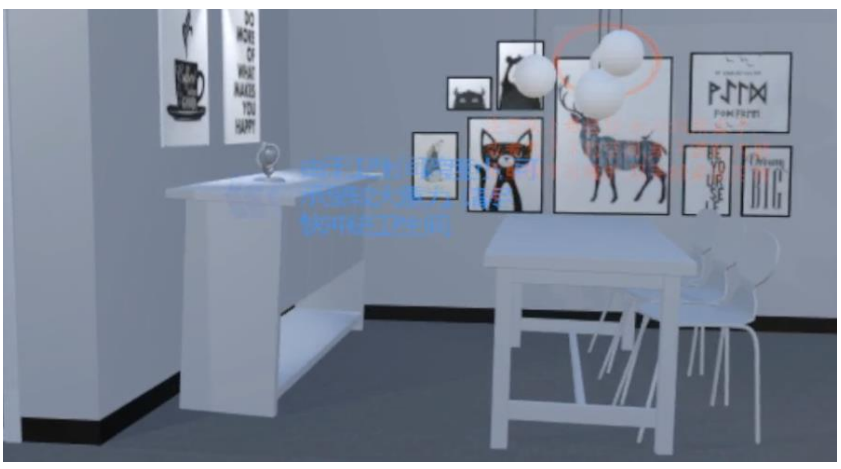

Figure 1: Building-shaking simulation

In traditional evacuation drills in real world, evacuees can hardly see fire and smoke during training, which may really exist accompanied with real earthquake disaster. To reduce this gap between real evacuation and earthquake drill, fire and smoke is represented in virtual scenario by using particle system of virtual reality engine, as shown in Figure 2.

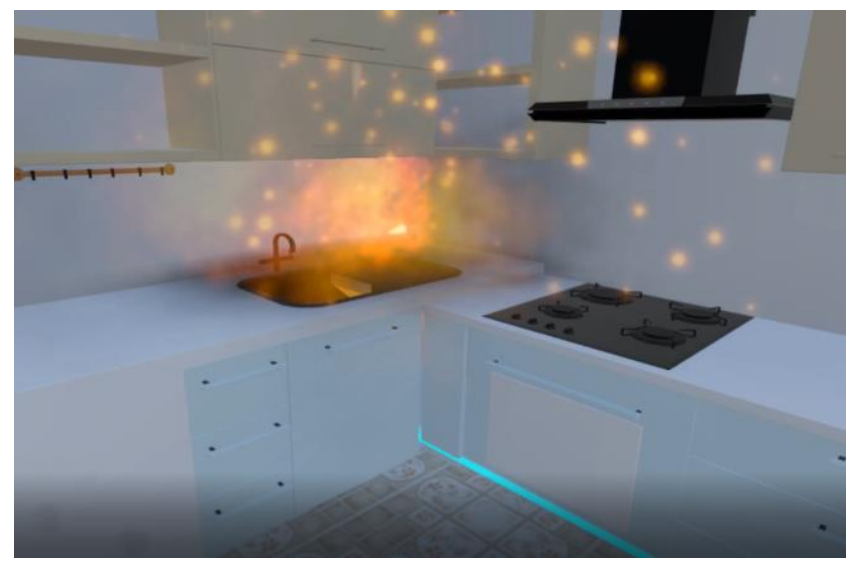

Figure 2: Simulation of fire and smoke caused by earthquake

Our learning outcome is to provide participants with knowledge on how to respond and evacuate safely during the main shock. Signal instructions are provided to provide wayfinding guidance during the training procedure in the immersive environment as illustrated in Figure 3. Unexpectedly blocked exit pathways are also included in virtual environments as well. In emergence of strong earthquake shaking, evacuees must learn to immediately protect themselves first from potential serious injury for unsecured object around them could topple or falling caused by severe shaking. Guidance is provided to advice player to stay low and cover his head and neck with arms and hands, as shown in Figure 4.

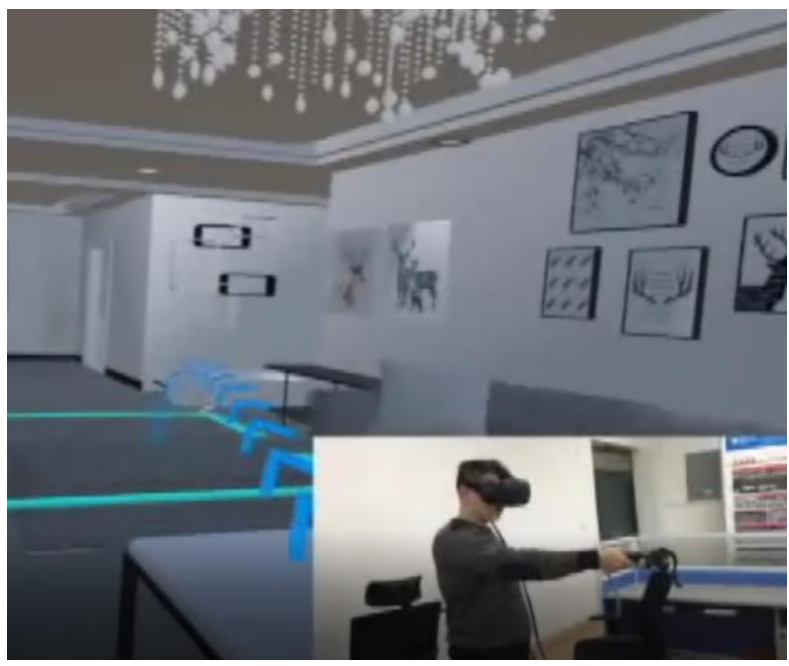

Figure 3: Guidance for wayfinding

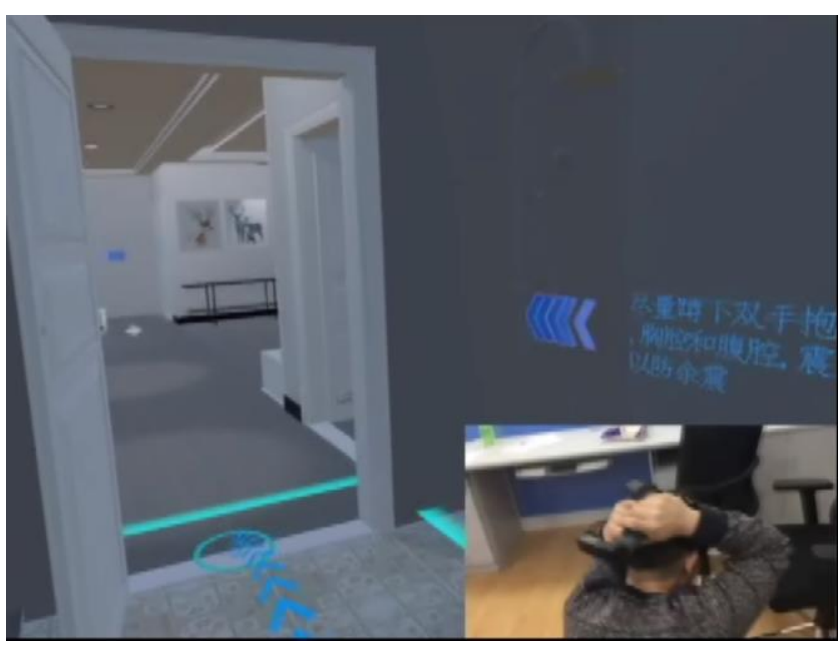

Figure 4: Guidance for keeping safety position

\subsection{Investigation and Evaluation}

Besides providing instructions and training exercising to participants, our prototype also provides the ability of investigating players' behaviors, which allows the assessment of players' ability of decision-making of wayfinding and exit choice in emergency. As one of the advantages, our VR-based prototype can provide experimental control to recognize the players' reaction. To simulate the emergency of the real earthquake, in virtual scenarios, fire and smoke is generated randomly to block the primary evacuation routes of the building. As a consequence, players may have to find the alternative escape routes. An effective evacuation route algorithm is proposed to provide feedback for enhancing earthquake evacuee safety.

\subsubsection{Best Escape Path Mathematical Models}


First, mathematical model is developed to find the best escape path automatically. This best path can provide player with evaluation function by comparing with his/her evacuation route recorded by simulator.

The best escape path mathematical model searches for all passable paths $P$ between the location point and the safety point of the trapped person (the evacuee), and then selects the path with the shortest equivalent length as the best path, which lead to the maximum escape probability. Therefore, the best escape path between the trapped person's location point $s$ and the safety point $j$ should satisfy the objective function:

$F=\left\{\begin{array}{c}0 \quad(s=j) \\ \min D_{s j}(s \neq j)\end{array}\right.$

Where $D s j$ is the equivalent length of all passable paths from the location point $s$ of the trapped person to the safety point $j$. When the trapped person reaches the safety point, the objective function $F=0$.

From the location point $s$ to the safety point $j$, all of the passable paths are composed of $n$ arc segments, which are included in all of the passable paths $P$, the calculation formula of the walking path equivalent length $D s j$ is

$D_{s j}=\sum_{i=1}^{n} d_{R_{i}}\left(R_{i} \in P\right)$

Where $R_{i}$ is the arc between adjacent nodes in the channel network; $d_{R_{i}}$ is the equivalent length of the channel $R_{i}$.

The calculation of the channel equivalent length adds a safety factor $\omega$ on the base of the various factors affecting the personnel's travel. To calculate the equivalent length of the arc, we use the method by multiplying each impact factors $\varphi$ by the actual length of the channel and then weighting it. The formula for calculating the equivalent length of $R_{i}$ is:

$d_{R_{i}}=\frac{1}{\omega_{R_{i}}}\left[1+\varphi_{1_{\left(R_{i}\right)}}+\varphi_{2_{\left(R_{i}\right)}}+\varphi_{3_{\left(R_{i}\right)}}+\cdots+\varphi_{m_{\left(R_{i}\right)}}\right] * l_{R_{i}}$

Where $\varphi_{m_{\left(R_{i}\right)}}$ is the safety factor of $R_{i} ; \varphi_{m_{\left(R_{i}\right)}}$ is the m-th disaster avoidance factor (temperature, toxic smoke concentration, etc.) of $R_{i} ; l_{R_{i}}$ is the physical length of $R_{i}$. The safety factor $\omega$ (illumination, channel width, etc.) is inversely proportional to the channel equivalent length, and other avoidance impact factors $\varphi$ are directly proportional to the channel equivalent length.

Bring (2)、(3) into (1) to get the optimal escape path mathematical model for the trapped person from the location point $s$ to the safety point $j$ :

$\mathrm{Y}=\left\{\begin{array}{c}\sum_{i=1}^{n} \frac{1}{\omega_{R_{i}}}\left[1+\varphi_{1_{\left(R_{i}\right)}}+\varphi_{2_{\left(R_{i}\right)}}+\varphi_{3_{\left(R_{i}\right)}}+\cdots+\varphi_{m_{\left(R_{i}\right)}}\right] * d_{R_{i}}=0(j=s) \\ \min _{j \neq s} \sum_{i=1}^{n} \frac{1}{\omega_{R_{i}}}\left[1+\varphi_{1_{\left(R_{i}\right)}}+\varphi_{2_{\left(R_{i}\right)}}+\varphi_{3_{\left(R_{i}\right)}}+\cdots+\varphi_{\left.m_{\left(R_{i}\right.}\right]}\right] * d_{R_{i}} * z_{s j}(j \neq s)\end{array}\right.$

$z_{s j}$ is a variable of $0 \sim 1$. When $R_{i}$ is included in all implementable paths $P, z_{s j}=1$, and $z_{s j}=0$
(1) Safety factor $\omega$. There are two main indicators that affect the safety of the escape process: one is the channel structure attribute, which belongs to static data; the other is fire disaster factor caused by an earthquake, mainly temperature, $\mathrm{CO} 2$, CO, O2 and toxic smoke flow, etc. (Chen and Kong 2010), which is dynamic data and acquired by the monitoring system in real time.

According to whether a fire occurs, the safety factor $\omega$ is divided into two levels. When $\omega=0$, the channel is fired and impassable; when $\omega=1$, the channel is no on fire and passable, as shown in Table 1.

Table 1 Confirmation form of traffic condition

\begin{tabular}{cccc}
\hline $\begin{array}{c}\text { Whether a } \\
\text { fire broke out }\end{array}$ & $\begin{array}{c}\text { Safety fac- } \\
\text { tor }\end{array}$ & $\begin{array}{c}\text { Danger } \\
\text { Level }\end{array}$ & $\begin{array}{c}\text { Traffic condi- } \\
\text { tion }\end{array}$ \\
\hline Yes & 0 & Danger & Impassible \\
No & 1 & Safe & Passable \\
\hline
\end{tabular}

(2) The calculation of the disaster avoidance factor $\varphi$. According to the actual situation of the building, the main factors affecting the escape of personnel are channel width, channel lighting, objects, and personnel walking modes. Channel illumination and personnel walking mode are the two factors that have greater impacts on equivalent speed, which are used as two impact factors of the equivalent length of the escape path. The value of the impact factor is deduced by the escape speed:

$\varphi_{m}=\frac{u_{0}-u_{k}}{u_{0}}$

Where $u_{0}$ is the walking speed in the free state; $u_{k}$ is the walking speed in the non-free state.

According to the on-site simulation and actual measurement when there is no earthquake, the speed of the staff in different situations is measured. In the case of dark passages, dark or unfamiliar stairs, the speed of travel is greatly reduced; and in the case of lighting or familiarity with the environment, the speed of escape is greatly increased. When the impact factor $\varphi$ is negative, it indicates that the influencing factor promotes the speed of the staff. The impact factor calculation results are shown in Table 2.

According to the formula of the equivalent length, the length of the channel is changed based on the channel network diagram. The channel equivalent network diagram is constructed as shown in Figure 5, and the Dijkstra algorithm is used to solve the optimal path (Wang et al. 2014; He et al. 2015; Liu et al. 2011).

Table 2 Calculation results of impact factor

\begin{tabular}{ccc}
$\begin{array}{c}\text { Walking environ- } \\
\text { ment }\end{array}$ & Walking speed & Impact factor \\
\hline Free walking & 1.33 & 0.00 \\
Trot & 3.00 & -1.25
\end{tabular}




$\begin{array}{ccc}\text { Run fast } & 5.50 & -2.76 \\ \text { Passage dark } & 0.70 & 0.47 \\ \text { Stairway dark } & 0.30 & 0.77 \\ \text { Stair lighting } & 0.50 & 0.60\end{array}$

\subsubsection{Simulation Analysis}

Fire exits of a floor is simulated in Figure 5.

Assume that there is a fire at node G in Figure 5, channel DG, GJ, and part of GH, GI are fire areas and impassable. There are 11 nodes, A, B, C, E, F, H, I, K, L, M and N, are safe for evacuating. Supposing that person is trapped at node $\mathrm{A}$ and needs to reach the exit point - node $\mathrm{N}$, and the distance between the non-adjacent nodes is $+\infty$, the distance between the nodes is shown in Table 3 .

The equivalent length of the channel can be calculated based on the data in Table 3 in conjunction with the channel influencing factors and the safety factor. The three influencing factors that mainly affect the equivalent speed of the staff are selected: channel width $\left(\varphi_{1}\right)$, channel illumination $\left(\varphi_{2}\right)$, and walking mode $\left(\varphi_{3}\right)$. When factor is negative, it indicates that the influencing factor has a promoting effect on the equivalent speed. Since the channel $\mathrm{MN}$ is a shared channel leading to node $\mathrm{N}$ in two directions from node $\mathrm{L}$ and $\mathrm{K}$, the equivalent speed may be reduced by the panic crowded people. In this situation the influencing factor is up to 0.4. Equivalent length is calculated in Table 4.

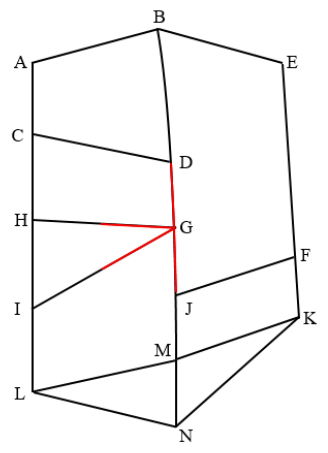

Figure.5 Path diagram of building floor

Table 3 Distance of adjacent nodes ( $\mathrm{m}$ )

\begin{tabular}{|c|c|c|c|c|c|c|c|c|c|c|c|}
\hline Node & $A$ & $B$ & $C$ & $E$ & $F$ & $H$ & $I$ & $K$ & $L$ & $M$ & $N$ \\
\hline$A$ & 0 & 130 & 30 & $\infty$ & $\infty$ & $\infty$ & $\infty$ & $\infty$ & $\infty$ & $\infty$ & $\infty$ \\
\hline$B$ & 130 & 0 & $\infty$ & 150 & $\infty$ & $\infty$ & $\infty$ & $\infty$ & $\infty$ & $\infty$ & $\infty$ \\
\hline$C$ & 38 & $\infty$ & 0 & $\infty$ & $\infty$ & 140 & $\infty$ & $\infty$ & $\infty$ & $\infty$ & $\infty$ \\
\hline$E$ & $\infty$ & 150 & $\infty$ & 0 & 155 & $\infty$ & $\infty$ & $\infty$ & $\infty$ & $\infty$ & $\infty$ \\
\hline$F$ & $\infty$ & $\infty$ & $\infty$ & 160 & 0 & $\infty$ & $\infty$ & 120 & $\infty$ & $\infty$ & $\infty$ \\
\hline$H$ & $\infty$ & $\infty$ & 140 & $\infty$ & $\infty$ & 0 & 135 & $\infty$ & $\infty$ & $\infty$ & $\infty$ \\
\hline$I$ & $\infty$ & $\infty$ & $\infty$ & $\infty$ & $\infty$ & 135 & 0 & $\infty$ & 50 & $\infty$ & $\infty$ \\
\hline$K$ & $\infty$ & $\infty$ & $\infty$ & $\infty$ & 120 & $\infty$ & $\infty$ & 0 & $\infty$ & 142 & 137 \\
\hline$L$ & $\infty$ & $\infty$ & $\infty$ & $\infty$ & $\infty$ & $\infty$ & 120 & $\infty$ & 0 & 144 & 146 \\
\hline$M$ & $\infty$ & $\infty$ & $\infty$ & $\infty$ & $\infty$ & $\infty$ & $\infty$ & 142 & 144 & 0 & 42 \\
\hline$N$ & $\infty$ & $\infty$ & $\infty$ & $\infty$ & $\infty$ & $\infty$ & $\infty$ & 137 & 146 & 42 & 0 \\
\hline
\end{tabular}

Table 4 Calculation of equivalent length

\begin{tabular}{ccccccc}
\hline Aisle & Actual length $/ \mathrm{m}$ & $\varphi_{1}$ & $\varphi_{2}$ & $\varphi_{3}$ & $\omega$ & Equivalent length/m \\
\hline $\mathrm{AB}$ & 130 & 0 & 0.4 & 0.1 & 1.0 & 195 \\
\hline
\end{tabular}




\begin{tabular}{|c|c|c|c|c|c|c|}
\hline $\mathrm{AC}$ & 30 & 0 & 0.6 & 0.2 & 1.0 & 54 \\
\hline $\mathrm{BE}$ & 150 & 0 & -0.2 & 0.1 & 1.0 & 135 \\
\hline $\mathrm{CH}$ & 140 & 0 & 0.2 & 0.55 & 1.0 & 245 \\
\hline $\mathrm{HL}$ & 135 & 0 & 0.2 & 0.55 & 1.0 & 236.25 \\
\hline IL & 50 & 0 & -0.4 & -0.2 & 1.0 & 20 \\
\hline $\mathrm{EF}$ & 155 & 0 & -0.2 & 0.1 & 1.0 & 139.5 \\
\hline FK & 120 & 0 & 0.4 & 0.2 & 1.0 & 192 \\
\hline $\mathrm{KM}$ & 142 & 0 & 0.2 & -0.2 & 1.0 & 142 \\
\hline $\mathrm{KN}$ & 137 & 0 & 0.2 & -0.5 & 1.0 & 95.9 \\
\hline $\mathrm{MN}$ & 42 & 0.4 & 0.4 & 0.4 & 1.0 & 92.4 \\
\hline LM & 144 & 0 & 0.2 & 0.6 & 1.0 & 259.2 \\
\hline $\mathrm{LN}$ & 146 & 0 & 0.2 & 0.4 & 1.0 & 233.6 \\
\hline
\end{tabular}

According to the results of Table 4, Dijkstra algorithm is used to find the shortest path between node $\mathrm{A}$ and node $\mathrm{N}$ : $\mathrm{A}->\mathrm{B}->\mathrm{E}->\mathrm{F}->\mathrm{K}->\mathrm{N}$. Table 5 shows the actual length and equivalent length of the four safety paths between node $\mathrm{A}$ and node $\mathrm{N}$.

Table 5 Comparison of the actual length with the equivalent length of the safety path

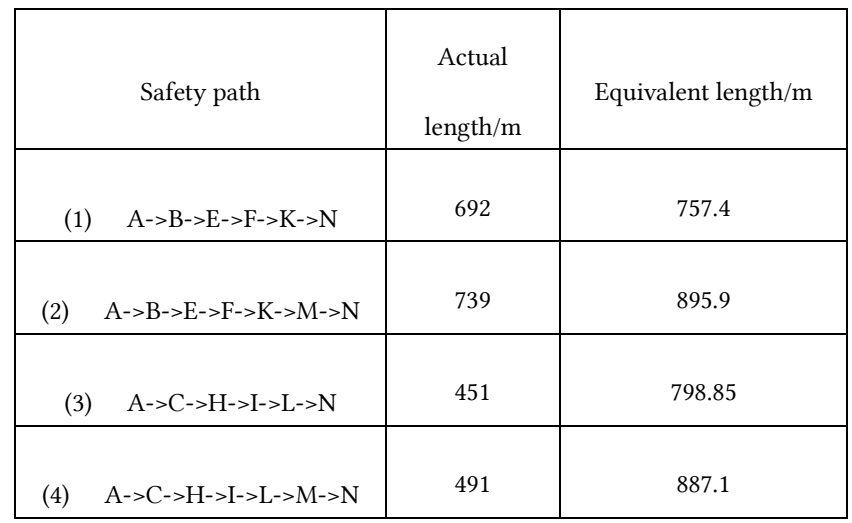

It can be seen from Table 5 that the actual length of the path No. 3 is the shortest, while the path equivalent length of the No. 1 is the shortest. Therefore, under the common influence of channel width, channel illumination, and walking mode, the actual shortest path and the channel equivalent length shortest path are not necessarily the same. That is, the actual shortest path does not mean the best escape path, and in this case, path No. 1 should be selected as the optimal escape path.

\section{Implementation}

We utilized HTC Vive in our system as the HMD device to provide a high immersive experience. HTC Vive consists of three components: one adjustable headset, two base stations and two wireless hand controllers. The exact location and orientation of the headset and controllers can be tracked in virtual space, which provide us the motion data of the participants during evacuation drills. Hand controllers enable the users to interact with the $3 \mathrm{D}$ objects within the earthquake scenarios naturally and intuitively and provide tactile feedback to simulate shaking at the same time. The headset is used to control the camera view in the virtual space. First person view is used to provide more immersive and realistic experience.

Once the training simulation begins, player's view point follows the movement of headset in the real world. Fire, smoke, ceiling vibration is added to the headset display as the UI information to improve the user experience. All the 3D models and animations are created in Maya 2018. We integrated and developed the entire system in Unity 2018. The architecture of the VR prototype is illustrated in Figure.6.

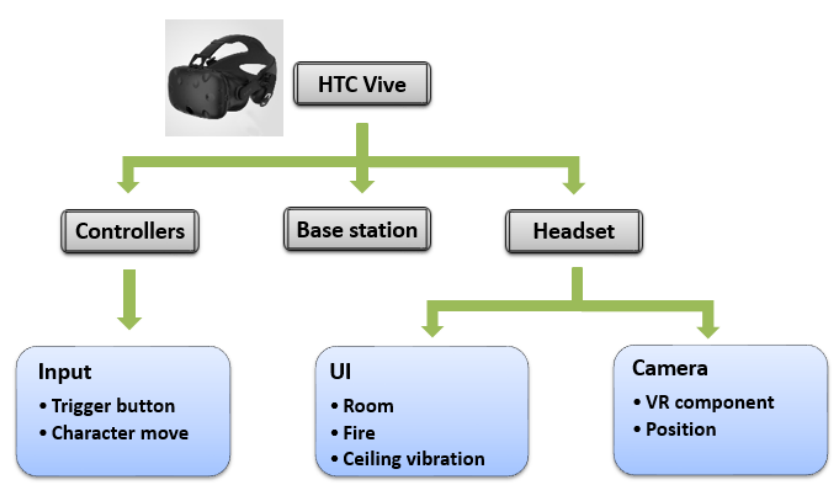

Figure.6 The architecture of the VR prototype 


\section{Prototype Evaluation}

A pilot study participated by 40 college student volunteers $(20$ males and 20 females) has been conducted for both purposes of pedagogical evaluation and usability evaluation. Mixed evaluating approach was adopted from the perspectives of both the subjective and objective factors: participants' performances during virtual evacuation training were gathered and analyzed based on marks and correctness; questionnaire was given to each participant after trails to provide feedback on the system usability.

\subsection{Pedagogical Evaluation}

For the purpose of comparative case studies and investigating the educational effect, the study required 40 participants equally divided into two groups. Each group consisted of 10 males and 10 females randomly recruited on campus with the same age and background. Group One is the experimental group, receiving training using our VR prototype. Group Two is the control group, using textbook to learn evacuee safety knowledge traditionally.

Both groups were given the same time (1 hour) to review the textbook or practice in the VR environment. Afterwards, the two groups were tested for evaluating training effect and conducting comparison. The test involved two parts: Part One is the general knowledge quiz, developed by the earthquake safety knowledge manual issued by government, with full score of 50 points. Part Two is drilling practice in the VR prototype with full score of 50 points. At the commence of this part, participants in Group Two were trained to familiarise themselves with VR devices (e.g., the hand controller and the Stereoscopic helmet) and VR environment after detailed explanation of the prototype. Judgment was conducted by experienced teachers. Average score of each group is shown in Figure 7.

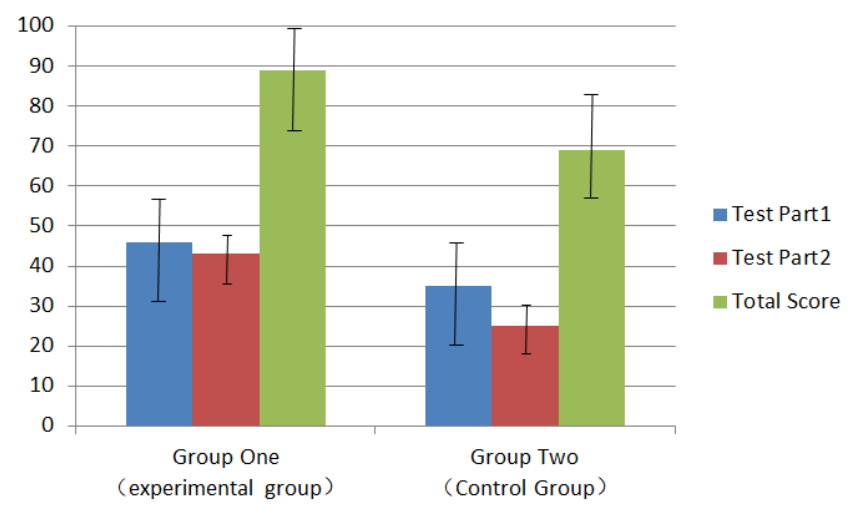

Figure.7 Mean and variance results of the two groups

The result shows that that, for test Part One, the mean value of the first part of the knowledge quiz of Group One (experimental group) is significantly higher than Group Two (control group), which shows that the use of our VR training prototype can better improve the learning effect of earthquake safety training than the traditional educational approach. For the second part of the VR drilling practice, it is clearly shown that the result of the experi- mental group significantly higher than control group, which indicates that participants who received effective training using our VR prototype achieved significantly better results than the ones who only read textbook and seldom practiced in simulated emergency scenario. Overall result indicates the positive educational effect of our VR-based training prototype.

\subsection{Usability Evaluation}

After test, questionnaire was given to each participant, regarding system usability as well as his/her suggestions for improvement. The Likert scales were used for evaluation and open-ended questions were provided for suggestions to improve our prototype design. Six criterions were given for evaluating the usability including ease of use, precision, stability, naturalness, freedom of movement and effectiveness. For each criterion, participant was asked to score (1-5 scale; $1=$ poor satisfaction; $5=$ excellently satisfied). Figure 8 shows the positive feedback on our prototype usability. Most of the participants from the two groups held positive attitudes towards the user experience of the prototype. They enjoyed this novel and immersive training environment comparing with the traditional educational approaches.

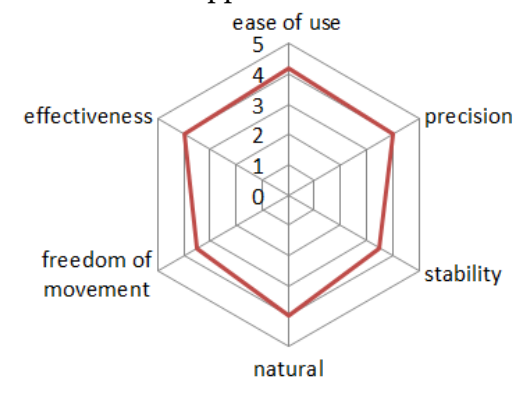

Figure.8 Mean scores for each criterion of usability (1Poor, 2-Fair, 3-Average, 4-Good, 5-Excellent)

\section{Conclusion and Discussion}

Scientists have tried many different ways of predicting earthquakes, but it is unlikely they can precisely tell when it will happen. Thus, enhancing evacuee safety is vital important for reducing the number of injuries and deaths from the disaster. This goal can be achieved by conduct effective education and training. Traditional training approaches, such as evacuation drills, have poor reality and interaction limitations and can hardly provide effective investigation and evaluation for participants. In this paper, a novel and effective VR-based training prototype system is designed to overcome these limitations. Out prototype can provide players with immersive virtual environment, mimic the damage in the emergency scenarios, provide guidance, investigate players' behaviors and give feedback effectively.

There are some improving works left to be carried on in the future. Networking and multiplayer support will be added using cloud resource to construct a distributed architecture, which enables players to participate simultaneously via internet connection just like the experience of Massively Multiplayer Online Game (MMOG). The distributed system architecture proposed by our 
previous work (Liang et al. 2016) will be utilized to support multiple HTC vive devices and to provide wider simulation space, as well as the effect of mental activity and the crowd movement in the evacuation performance evaluation (Liang et al. 2016).

Despite the advantages offered by our prototype system, there are still some limitations that need to be addressed. Shaking and ground rupture are the main effects created by earthquakes. We utilize the movement of furniture and the vibrations of the controller vibration motor to simulate shaking, which may not provide players real perceptible shaking effect because of the lack of physical stimuli. Another limitation is that the use of HMD obstructs players' vision to investigate their postures in the virtual scenarios, which may weaken the pedagogical function, especially in the scenario of severe earthquake training, evacuees must learn to protect themselves by keeping proper body posture, such as staying low and covering head and neck with arms and hands.

At the same time of providing players with novel training experience, immersive VR technologies still suffer several limitations, such as motion sickness and the problem of dizziness when switching viewpoints, which are expected be addressed by the improvement of the VR devices in near future.

\section{ACKNOWLEDGMENTS}

The research leading to these results has received funding from the National Natural Science Foundation of China (NSFC, 61872439). The authors acknowledge partial support from the Key Scientific Research Projects of Henan Province of China (18210221055).

\section{REFERENCES}

Bernardini G., D’Orazio M., and Quagliarini E., (2016) .Towards a “behavioural design” approach for seismic risk reduction strategies of buildings and their environment. Safety Science, 86, pp.273- 294.

Bertram J., Moskaliuk J., Cress U., (2015). Virtual training: making reality work? Computers in Human Behavior, vol. 43, pp. 284-292, Feb. 2015. DOI: 10.1016/j.chb.2014.10.032

Bhagat K., Liou W.K., Chang C.Y., (2016). A cost-effective interactive 3D virtual reality system applied to military live firing training. Virtual Reality, vol. 20, pp. 127-140,. DOI: 10.1007/s10055-016-0284-x

Chen N. , Kong W., (2010). Research on optimal escape and rescue routes of mine fire. Industrial Safety and Environmental Protection, 36(11):40-42.

Chittaro L. and Buttussi F., (2015). Assessing Knowledge Retention of an Immersive Serious Game vs. a Traditional Education Method in Aviation Safety. IEEE transactions on visualization and computer graphics, 21(4), pp.529-38.

Foronda C. L., Shubeck K., Swoboda S. M.; Hudson K. W., Budhathoki C., Sullivan N. and Hu C., (2016). Impact of Virtual Simulation to Teach Concepts of Disaster Triage. Clinical Simulation in Nursing, vol. 12, pp. 137-144.

Grant L.B., (2001). Living with earthquakes in california: A survivor's guide. Eos, Transactions American Geophysical Union, 82(49):611-611.

Gwynne S.M.V., et al., (2016). Pros and Cons of Egress Drills. In Interflam 2016. London, UK.

Gwynne S.M.V., et al., (2017). Enhancing Egress Drills: Preparation and Assessment of Evacuee Performance, Fire and Materials, DOI: 10.1002/fam.2448

Gwynne S.M.V., K. E. Boyce, Kuligowski E. D., Nilsson D., Robbins A., Lovreglio R., Roy-Poirier A. and Thomas J. R., (2017). Enhancing Egress Drills: Preparation and Assessment of Evacuee Performance. Fire and Materials, DOI: $10.1002 /$ fam. 2448 .

He C., Yang W., Yang G.,et al, (2015). A shortest path algorithm based on improved Dijkstra algorithm. Value Engineering, 2015 (15):204-206.

Jones L.M., (1994). Foreshocks, aftershocks, and earthquake probabilities: Accounting for the landers earthquake. Bulletin of the Seismological Society of America, 84(3), pp.892-899.

Koubaridis A., (2011). Christchurch quake: 'Buildings just piled on top of people'. New Zealand Herald. Retrieved Sep, 2018.
Li, C., Liang, W., Quigley, C., Zhao, Y., \& Yu, L. F. (2017). Earthquake safety training through virtual drills. IEEE Transactions on Visualization \& Computer Graphics, PP(99), 1-1.

Liang, H., Chang, J., Deng, S., Chen, C., Tong, R., \& Zhang, J. J. (2017). Exploitation of multiplayer interaction and development of virtual puppetry storytelling using gesture control and stereoscopic devices. Computer Animation \& Virtua Worlds, 28(5).

Liu J., Ma S., Ma S., (2011). Computation of the dynamic shortest path based on improved-Dijkstra algorithm. System Engineering-Theory and Practice,2011,31(6)

Lovreglio R., Fonzone A. and Dell'Olio L., L., (2016). A Mixed Logit Model for Predicting Exit Choice During Building Evacuations. Transportation Research Part A.

Lovreglio R., Gonzalez V., Amor R., Spearpoint M., Thomas J., Trotter M. and Sacks R., (2017). The Need for Enhancing Earthquake Evacuee Safety by using Virtual Reality Serious Games. Lean \& Computing in Construction Congress 2017, Heraklion, Crete, Greece.

Mitsuhara H., Inoue T., Yamaguchi K., Takechi Y., Morimoto M., Iwaka K., Kozuki Y. and Shishibori M., (2015). Web-based system for designing game-based evacuation drills. Procedia Computer Science, vol. 72, pp.277-284.

Olander, J. et al., (2017). Dissuasive exit signage for building fire evacuation. Applied Ergonomics, 59, pp.84-93.

Pan Z. G., Cheok A. D., Yang H. W., Zhu J. J., Shi J. Y., (2005). Virtual reality and mixed reality for virtual learning environments. Computers \& Graphics, vol. 30, pp. 20-28, 2016. DOI: 10.1016/j.cag.2005.10.004.

Ramirez M., Kubicek K., Peek-Asa C., and Wong M., (2009). Accountability and assessment of emergency drill performance at schools. Family and Community Health, 32(2).

Ronchi, E. et al., (2016). A Virtual Reality experiment on flashing lights at emergency exit portals for road tunnel evacuation. Fire Technology, 52(3), pp.623-647.

Rüppel U. and Schatz K., (2011). Designing a BIM-based serious game for fire safety evacuation simulations. Advanced Engineering Informatics, 25(4), pp.600-611.

Tanes Z. and Cho H., (2013). Goal setting outcomes: Examining the role of goal interaction in influencing the experience and learning outcomes of video game play for earthquake preparedness. Computers in Human Behavior, 29(3), pp.858-869.

USGS (2018). the Great 1906 San Francisco Earthquake. https://earthquake.usgs.gov/earthquakes/events/1906calif/18april/. Retrieved Sep,2018.

Wang J., Zhang Y., Li Y., (2014). Mathematical modeling and algorithm's research of optimal hedge underground route's GIS network analysis. Journal of China Coal Society, 39(S2):411-415.

Williams-Bell F.M., et al., (2015). Using Serious Games and Virtual Simulation for Training in the Fire Service: A Review, Fire Technology, 51(3), pp.553-584.

Xu Z., Lu X. Z., Guan H., Chen C., Ren A. Z., (2014). A virtual reality based fire training simulator with smoke hazard assessment capacity. Advances in Engineering Software, vol. 68, pp. 1-8, Feb. DOI: 10.1016/j.advengsoft.2013.10.004. 